\title{
Hardness and Microstructure of Sterling Silver Cast by Sloped Cooling Plate Method
}

\author{
Natthaphol Chomsaeng $^{1 *}$ and Nuchthana Poolthong ${ }^{2}$ \\ ${ }^{1}$ Jewelry Materials Research and Development Unit, Faculty of Gems, Burapha \\ University, Chanthaburi Campus, Chanthaburi 22170, Thailand \\ ${ }^{2}$ Division of Materials Technology, School of Energy, Environment and Materials, \\ King Mongkut's University of Technology Thonburi, Bangkok 10140, Thailand \\ *Corresponding author. E-mail: natthapholc@gmail.com \\ https://doi.org/10.12982/CMUJNS.2017.0020
}

\begin{abstract}
Semi-solid casting was introduced to improve the mechanical properties of sterling silver by sloped cooling plate technique. Ag alloys (93.5 wt\%) were cast from an induction furnace at $1,000^{\circ} \mathrm{C}$ onto a sloped cooling plate. The pouring angles and distances were 30-60 degree and 200-250 $\mathrm{mm}$, respectively. Effects of pouring angles and casting distances on hardness and microstructure of the sterling silver were investigated. Then, the solution was treated, followed by quenching and artificial aging. The specimens were checked with Vickers microhardness tester, light microscope, and scanning electron microscope (SEM). Hardness of the as-cast sample from the semi-solid process was 63-78 $\mathrm{HV}$. The 60-minute aged sample that was cast at a $30^{\circ}$ angle and $250 \mathrm{~mm}$ distance obtained the maximum hardness of $148.5 \mathrm{HV}$. The microstructure of the as-cast sample consisted primarily of $\alpha$-phase and eutectic structure. A spheroidal and short dendrite structure was formed in the as-cast sample. After aging, precipitation occurred substantially within the a-phase. SEM images revealed that the aged sample with the highest hardness contained Cu-rich and Ag-rich precipitates in the $\alpha$-phase.
\end{abstract}

Keywords: Sterling silver, Semi-solid casting, Aging, Hardness

\section{INTRODUCTION}

Market demand for silver jewelry has been increasing, due to its lower price compared to jewelry made of other precious metals. Since pure silver is soft, with a hardness of $\sim 55 \mathrm{HV}$, it is usually alloyed with $7.5 \mathrm{wt} \% \mathrm{Cu}$ to create sterling silver (Olver, 2001) with a hardness of 60-70 HV (Chanmuang et al., 2012). Hardening strengthens the alloy. $\mathrm{Cu}(8.8 \mathrm{wt} \%)$ is soluble in silver at $775^{\circ} \mathrm{C}$ (Nisaratanaporn S. and Nisaratanaporn E., 2003). The resultant alloy has a microstructure of an alpha phase $(\alpha)$ and a eutectic phase. Adding a third element, such as $\mathrm{Zn}, \mathrm{Si}, \mathrm{Ge}, \mathrm{Mn}$, Ir, or B, can improve their properties and cast ability. 
Semi-solid casting is a promising process in the foundry industry used to improve the structures and properties of alloys (Yu et al., 1999; Kapranos et al., 2000; Mao et al., 2001; Cavaliere et al., 2004; Poolthong et al., 2003; 2004; Ramadan et al., 2006; Wiengmoon et al., 2007). In this process, molten alloy is partially solidified before shaping. This casting technology can manufacture near net shape parts and reduce the machining process. Semi-solid casting includes several techniques, such as electromagnetic stirring (Kapranos et al., 2000; Cavaliere et al., 2004), magneto-hydrodynamic stirring (Mao et al., 2001), mechanical stirring (Yu et al., 1999), and pouring molten-metals onto a sloped cooling plate (Poolthong et al., 2003; 2004). Usually, high melting point alloys is hard to cast by semi-solid method. However, the sloped cooling plate method can produce a fine globular grain structure in both high- and low-melting point alloys (Ramadan et al., 2006).

This study investigated the microstructure and hardness of sterling silver cast by sloped cooling plate method. The microstructure of as-cast and aged samples was studied using OM and SEM. The hardness was tested by Vickers microhardness tester.

\section{MATERIALS AND METHODS}

\section{Casting}

Silver alloy with $93.5 \mathrm{wt} \% \mathrm{Ag}$ and $6.5 \mathrm{wt} \% \mathrm{Cu}$ was melted in a graphite crucible within an induction furnace at $1,000^{\circ} \mathrm{C}$. The molten alloy was then cast by pouring on a sloped cooling plate into a plaster mold heated at $350^{\circ} \mathrm{C}$. A schematic of the semi-solid casting process with the sloped cooling plate technique is shown in Figure 1. In the pouring step, we varied the length $(200-250 \mathrm{~nm})$ and inclination $\left(30-60^{\circ}\right)$ of the semi-circular cooling plate. The plate was also coated with a thin layer of gypsum plaster to prevent the solidified alloys from sticking. A pneumatic rod was used to press the molten alloy into the plaster mold, as shown in Figure 1.

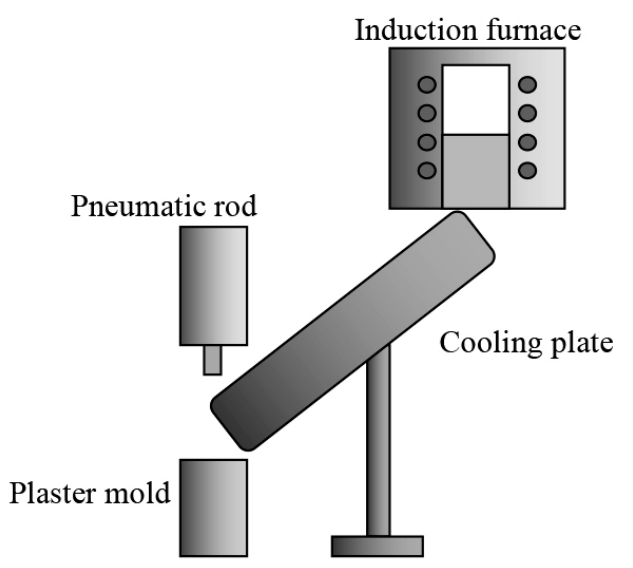

Figure 1. Schematic diagram of the semi-solid casting equipment with cooling plate. 


\section{Heat treatment}

As-cast specimens were heated in an electrical furnace to the desired temperature at a heating rate of $3^{\circ} \mathrm{C} / \mathrm{min}$. Solution treatment was performed at $750^{\circ} \mathrm{C}$ for 60 minutes, followed by quenching in water at room temperature. Furthermore, artificial aging was performed by heating in an electric furnace at $300^{\circ} \mathrm{C}$ for 30 , 60 and 120 minutes, followed by quenching in water at room temperature.

\section{Microstructure investigation}

To investigate the microstructure of the specimens, before using light microscopy and scanning electron microscopy (SEM), the specimens were polished on silicon carbide papers down to 1,000 grit and polished consecutively with 6 and $1 \mu \mathrm{m}$ alumina paste. Chemical etching was achieved by a mixture of $0.5 \mathrm{~g}$ chromic acid and $0.5 \mathrm{ml}$ sulfuric acid in $50 \mathrm{ml}$ distilled water. The microstructure was observed with a Zeiss Axiovert 25 optical microscope and a JEOL JSM5910LV scanning electron microscope operated at $15 \mathrm{kV}$ with a working distance of 11 $\mathrm{mm}$.

\section{Hardness measurement}

The specimens prepared in the step above were also used to measure micro-hardness by an ESEWAY 400 series hardness tester. The hardness testing was performed on an etched surface of the specimens using a $200 \mathrm{gf}$ load and 10 seconds indenting time. Mean values were calculated based on five measurements.

\section{RESULTS}

The microstructure as observed by light microscopy of all as-cast samples, as shown in Figure 2, consisted mainly of the primary $\alpha$-Ag and the eutectic structure of $\mathrm{Ag}$ and $\mathrm{Cu}$. Spheroidal and short dendrite primary $\alpha$-Ag was observed in the sample with a $250 \mathrm{~mm}$ pouring distance, while only dendrite structures were formed with a $200 \mathrm{~mm}$ pouring distance. The spheroidal size was about 20-50 $\mu \mathrm{m}$.

After aging at $300^{\circ} \mathrm{C}$ for 30,60 , and 120 minutes, the microstructures of the specimens differed from that of the as-cast condition (Figure 3). The Ag-rich phase appeared, while the eutectic phase disappeared. A new grain boundary was observed, as shown in the specimen aged for 60 minutes after casting at $45^{\circ}$ and at a distance of $200 \mathrm{~mm}$.

Backscattering electron (BSE) micrographs of some of the aged samples are shown in Figure 4. The eutectic structure in all aged samples disappeared, because all samples were homogenized after solution treatment. After aging for 30-120 minutes, the small particles of the $\mathrm{Cu}-\mathrm{Ag}$ phase precipitated (revealed by a dark contrast), as shown in Figures 4 (A) and (B). In Figure 5, EDS point analysis showed the composition of the particles and the matrix. Depending on semi-solid casting angles, which may cause differences in the Ag concentration, the silver and copper substitution altered after aging. Both Ag-rich and $\mathrm{Cu}$-rich particles were found in the sample cast at the $60^{\circ}$ semi-solid casting angle (Figure 5 

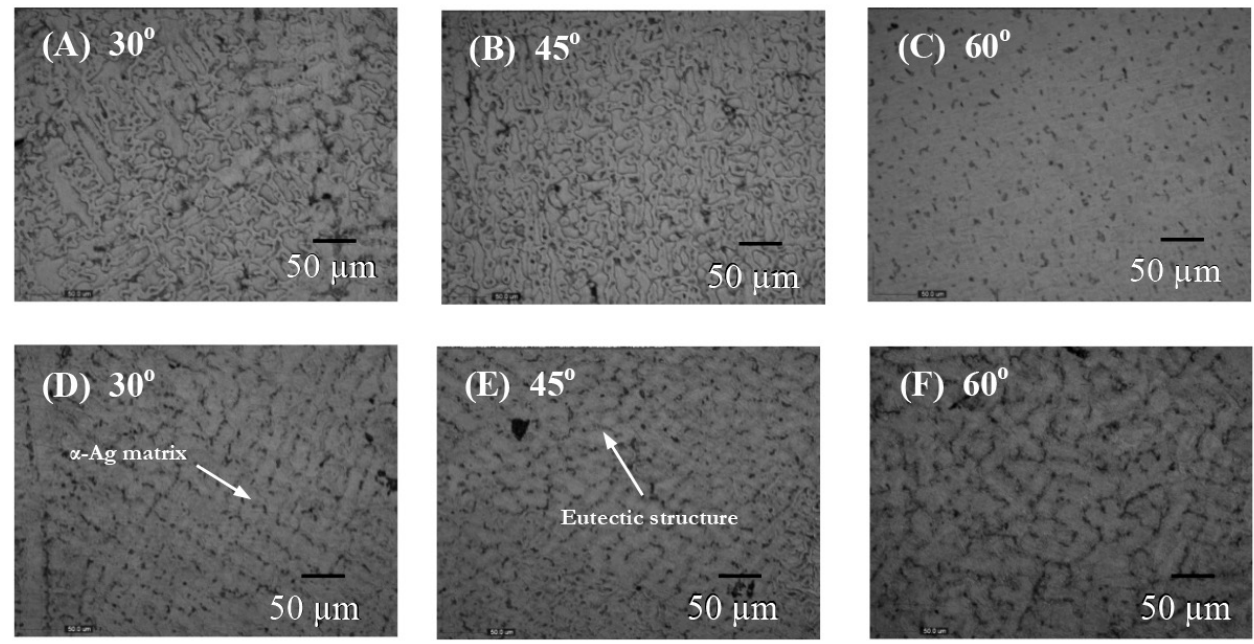

Figure 2. Microstructure of the as-cast sterling silver at various pouring angles; (A-C) prepared at a $200 \mathrm{~mm}$ pouring distance and (D-F) prepared at a $250 \mathrm{~mm}$ pouring distance.
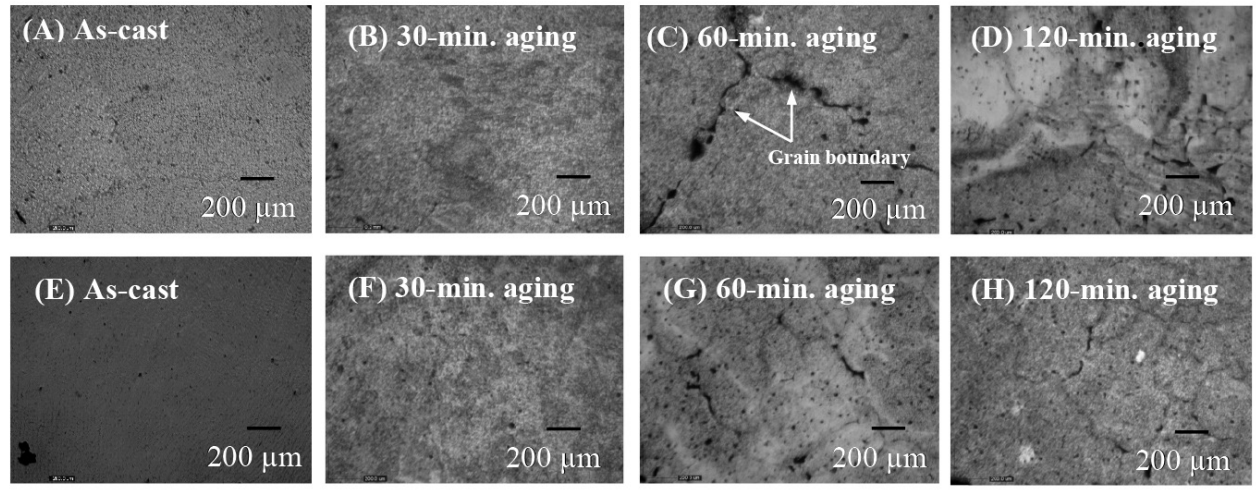

Figure 3. Microstructure of the as-cast and aged samples at various conditions; (A-D) as-cast and aged samples prepared at a $200 \mathrm{~mm}$ pouring distance and (E-H) as-cast and aged samples prepared at a $250 \mathrm{~mm}$ pouring distance. All samples were cast at a $45^{\circ}$ pouring angle.
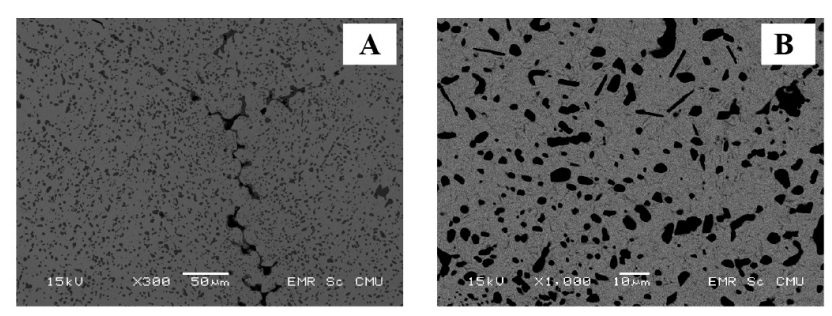

Figure 4. BEI-SEM images of aged samples with (A) 30 minutes and (B) 120 minutes aging. Samples (A) and (B) were cast at a $250 \mathrm{~mm}$ pouring distance with $60^{\circ}$ and $45^{\circ}$ pouring angles, respectively. 
(A)), while only $\mathrm{Cu}$-rich particles appeared in the $45^{\circ}$ sample (Figure $5(\mathrm{~B})$ ). The Ag-rich precipitate, 4-12 wt \% Ag, was formed in Cu-6 wt\% Al alloy (Carvalho et al., 2008). Moreover, oxygen was present in the area that contained $\mathrm{Cu}$.

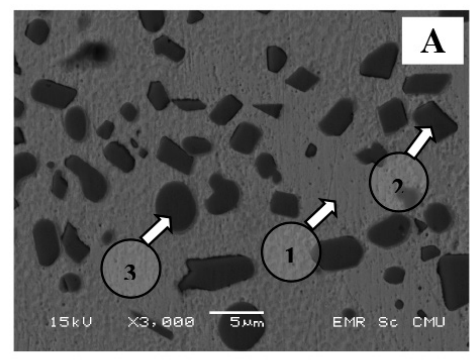

\begin{tabular}{cccc}
\hline Areas & \multicolumn{3}{c}{ Element (wt \%) } \\
\hline & $\mathbf{A g}$ & $\mathbf{C u}$ & $\mathbf{O}$ \\
\hline 1 & 100.00 & - & - \\
2 & 57.87 & 27.69 & 14.44 \\
3 & 11.65 & 62.83 & 25.52 \\
\hline
\end{tabular}

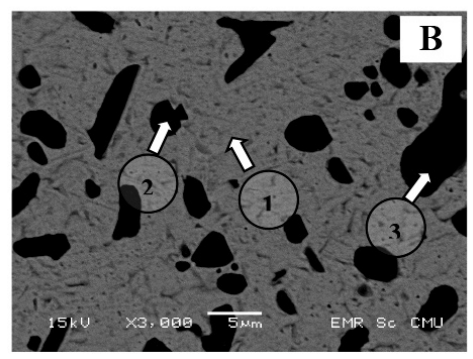

\begin{tabular}{cccc}
\hline Areas & \multicolumn{3}{c}{ Element (wt \%) } \\
\hline & $\mathbf{A g}$ & $\mathbf{C u}$ & $\mathbf{O}$ \\
\hline 1 & 100.00 & - & - \\
2 & 10.22 & 74.22 & 15.56 \\
3 & 2.32 & 72.41 & 25.27 \\
\hline
\end{tabular}

Figure 5. BEI-SEM images with EDS analhysis of the aged samples with (A) 30 minutes and (B) 120 minutes aging. Sample (A) and (B) were cast at a $250 \mathrm{~mm}$ pouring distance with $60^{\circ}$ and $45^{\circ}$ pouring angles, respectively.

The overall micro-hardness of the samples in the as-cast and aging conditions are shown in Figure 6. The highest hardness of the as-cast semi-solid sample was $78.48 \mathrm{HV}$. The highest hardness was obtained in the as-cast semi-solid sample that was cast at a $45^{\circ}$ pouring angle and $200 \mathrm{~mm}$ distance. Hardness depends on the cooling rate during solidification and microstructure formation. At a $45^{\circ}$ pouring angle, the as-cast sample formed a short dendrite structure, which improved the mechanical properties of the sterling silver. After aging, the hardness was two times that of the as-cast conditions.

\section{DISCUSSION}

A semi-solid casting process was used to improve the mechanical properties of sterling silver. Normally, with an investment casting process, Ag-rich dendrites form; however, with a semi-solid process, non-dendrite grains form. This morphology is typical for semi-solid casting, due to the shear force exerted on the melt as it flows down the cooling plate. For shorter pouring distances, dendrites might be able to grow in the liquid phase after the melt reaches the plaster mold. Casting at $45^{\circ}$ and a $200 \mathrm{~mm}$ distance provided the highest hardness, because of 


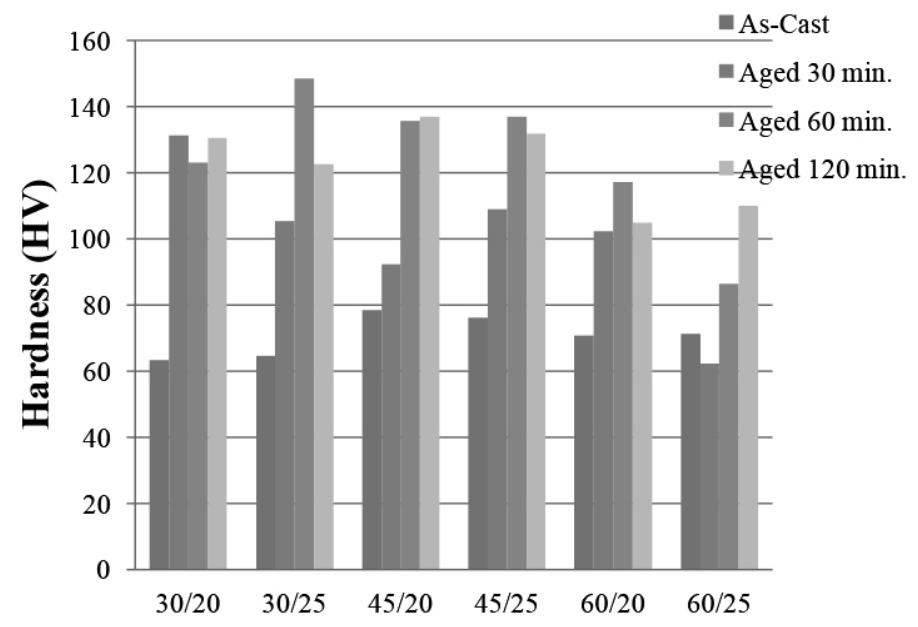

Casting condition

Figure 6. Vickers hardness of the as-cast and aged samples after 30,60, and 120 minutes aging at $300^{\circ} \mathrm{C}$ as prepared at different casting conditions (pouring angles/pouring distances).

Note: $30 / 20$ casting condition corresponds to a $30^{\circ}$ pouring angle and $200 \mathrm{~mm}$ pouring distance.

the proper solidification rate in the semi-solid stage. At the equilibrium cooling condition, the microstructure of the sterling silver was composed of only an $\alpha$ phase (Ag-rich). Conversely, at a non-equilibrium cooling condition, an eutectic structure was also found, due to the high cooling rate, as was observed in the semi-solid casting. Moreover, the semi-solid casting offered a spheroidal grain or short dendrite, resulting in higher hardness (Nisaratanaporn S. and Nisaratanaporn E., 2003). The hardness of the as-cast semi-solid sample was at least $18 \%$ higher than that of the sterling silver cast in a plaster mold or metal mold, 56 veruse 66 HV, respectively (Chanmuang et al., 2012).

For suitable age-hardening of sterling silver, hardness increased up to 140 $\mathrm{HV}$. One reason the aging process led to higher hardness was the substitution of alloying elements in the vacant areas of the matrix. Solution treatment above $745^{\circ} \mathrm{C}$ dissolved the eutectic structure into the silver matrix and the water-quenching step helped maintain the super-saturated solid solution. Furthermore, aging at $300^{\circ} \mathrm{C}$ lead to the formation of very fine $\mathrm{Cu}$-rich precipitates, as seen in the sample aged for 60 minutes, for example (see Figures 4 and 5). Oxygen was found in the $\mathrm{Cu}$-rich precipitate; this may be due to copper oxide formation. Fine precipitates considerably improved hardness of the sterling silver. Prolonged aging leads to over-aging, in which some properties of the alloys may deteriorate (Fischer, 2010). In some casting conditions, 120 minutes aging may be considered over-aging, since the hardness decreased. 


\section{CONCLUSION}

The microstructure of the as-cast sample consisted mainly of an $\alpha$-phase and an eutectic structure. Spheroidal and short dendrite structures were formed in the as-cast sample through semi-solid casting, especially at the $45^{\circ}$ and $250 \mathrm{~mm}$ condition. After aging, precipitation occurred substantially within the $\alpha$-phase, but it was not observable by light microscopy. An SEM image of the aged sample cast at $45^{\circ}$ and $60^{\circ}$ pouring angles with a $250 \mathrm{~mm}$ distance revealed $\mathrm{Cu}-\mathrm{Ag}$ phase distribution in the $\alpha$-phase; this enhanced hardness. Vickers micro-hardness of the as-cast samples cast by semi-solid process was about 63-78 HV. The highest hardness $(78.48 \mathrm{HV})$ was found in the sample cast at the $45^{\circ}$ and $200 \mathrm{~mm}$ condition, due to the spheroidal and short dendrite structures. The aged samples had higher hardness than that of the as-cast samples. The sample cast at $30^{\circ}$ and a $250 \mathrm{~mm}$ pouring distance with 60 minutes aging was the hardest, at $148.55 \mathrm{HV}$.

\section{ACKNOWLEDGEMENTS}

The authors gratefully acknowledge the Thailand Research Fund (TRF) for their financial support. The authors also thank Jurarat Jumkrong for her help in this research, as well as the Electron Microscopy Research and Service Center (EMRSC), Faculty of Science, Chiang Mai University for use of their facilities.

\section{REFERENCES}

Carvalho, T.M., Adorno, A.T., and Silva R.A.G. 2008. Ag-rich phase formation in the $\mathrm{Cu}-6 \mathrm{wt} \% \mathrm{Al}$ alloy with $\mathrm{Ag}$ additions. Journal of Physics and Chemistry of Solids. 69: 2025-2031. https://doi.org/10.1016/j.jpcs.2008.02.016

Cavaliere, P., Cerri, E., and Leo, P. 2004. Effect of heat treatment on mechanical properties and fracture behavior of a thixocast A356 aluminium alloy. Journal of Materials Science. 39: 1653-1658. https://doi.org/10.1023/B:JMSC.0000016165.99666.dd

Chanmuang, C., Kongmuang, W., Pearce, J.T.H., and Chairuangsri, T. 2012. Influence of casting techniques on hardness, tarnish behavior and microstructure of Ag-Cu-Zn-Si sterling silver jewelry alloys. Journal of Metals, Materials and Minerals. 22: 19-26.

Fischer-Bühner, J. 2010. Proceeding of the Santa Fe symposium on jewelry manufacturing technology. (pp. 29-47). Santa Fe, New Mexico.

Kapranos, P., Ward, P.J., Atkinson, H.V., and Kirkwood, D.H. 2000. Near net shaping by semi-solid metal processing. Materials and Design. 21: 387-394. https://doi.org/10.1016/S0261-3069(99)00077-1

Mao, W., Li Y., Zhao, A., and Zhong, X. 2001. The formation mechanism of non-dendriticprimary $\alpha$-Al phase in semi-solid $\mathrm{AlSi}_{7} \mathrm{Mg}$ alloy. Science and Technology Advanced Materials.2: 97-99. https://doi.org/10.1016/S14686996(01)00032-8 
Nisaratanaporn, S., and Nisaratanaporn, E. 2003. The anti-tarnishing, microstructure analysis and mechanical properties of sterling silver with Silicon addition, Journal of Metals, Materials and Minerals. 12: 13-18.

Olver, E., 2001. Jewelry making techniques book. (pp. 116-118). North Light Book, Cincinnati.

Poolthong, N., Nomura, H., and Takita, M. 2003. Effect of heat treatment on microstructure, wear properties and corrosion characteristics of semi-solid processed high chromium cast Iron. Internatioal Journal of Cast Metals Research. 16(6): 573-578. http://dx.doi.org/10.1080/13640461.2003.11819637

Poolthong, N., Nomura, H., and Takita, M. 2004. Effect of heat treatment on microstructure and properties of semi-Solid chromium cast iron. Materials Transaction. 45(3): 880-887. http://doi.org/10.2320/matertrans.45.880

Ramadan, M., Takita, M., and Nomura, H. 2006. Semi-solid processing of ultrahigh-carbon steel casting. Materials Science and Engineering A. 430: 285-291. https://doi.org/10.1016/j.msea.2006.05.132

Yu, Y.B., Song, P.Y., Kim, S.S., and Lee, J.H. 1999. Possibility of improving tensile strength of semi-solid processed A356 alloy by a post heat treatment at an extremely high temperature. Scripta Materialia. 41(7): 767-771. doi: 10.1016/S1359-6462(99)00215-8

Wiengmoon, A., Chairuangsri, T., Poolthong, N., and Pearce, J.T.H. 2007. Electron microscopy of semi-solid processed $27 \mathrm{wt} \% \mathrm{Cr}$ cast iron. Materials Science and Engineering A. 480:333-341. http://dx.doi.org/10.1016/j. msea.2007.07.043 